\title{
Western Skeptic vs Indian Realist. Cross-Cultural Differences in Zebra Case Intuitions
}

\author{
Krzysztof Sękowski $^{1}$ (D) A Adrian Ziółkowski ${ }^{1}$ (D) Maciej Tarnowski ${ }^{1}$ (D)
}

Accepted: 14 September 2021

(c) The Author(s) 2021

\begin{abstract}
The cross-cultural differences in epistemic intuitions reported by Weinberg, Nichols and Stich (2001; hereafter: WNS) laid the ground for the negative program of experimental philosophy. However, most of WNS's findings were not corroborated in further studies. The exception here is the study concerning purported differences between Westerners and Indians in knowledge ascriptions concerning the Zebra Case, which was never properly replicated. Our study replicates the above-mentioned experiment on a considerably larger sample of Westerners $(n=211)$ and Indians $(n=204)$. The analysis found a significant difference between the ethnic groups in question in the predicted direction: Indians were more likely to attribute knowledge in the Zebra Case than Westerners. In this paper, we offer an explanation of our result that takes into account the fact that replications of WNS's other experiments did not find any cross-cultural differences. We argue that the Zebra Case is unique among the vignettes tested by WNS since it should not be regarded as a Gettier case but rather as a scenario exhibiting skeptical pressure concerning the reliability of sense-perception. We argue that skepticism towards perception as a means of gaining knowledge is a trope that is deeply rooted in Western epistemology but is very much absent from Classical Indian philosophical inquiry. This line of reasoning is based on a thorough examination of the skeptical scenarios discussed by philosophers of the Indian Nyaya tradition and their adversaries.
\end{abstract}

Keywords Folk epistemology · Skepticism - Cross-cultural differences · Perception · Zebra case $\cdot$ Epistemic intuitions $\cdot$ Replication

Krzysztof Sękowski

k.sekowski@uw.edu.pl

1 Faculty of Philosophy, University of Warsaw, Warsaw, Poland 


\section{Introduction}

In their paper, which is believed to be one of the works that initiated experimental philosophy as a movement, Weinberg et al. (2001; hereafter: WNS) argue that the usage of thought experiments in epistemology is unreliable. They justify this claim by pointing out that we rely on our epistemic intuitions when evaluating thought experiments; however, as shown by their studies, these intuitions vary across various demographic variables (e.g. cultural background).

However, there remains one effect reported by WNS which has not yet been replicated. The issue concerns the differences between South Asians (Indians) and Westerners (represented by Americans in their study) elicited by the Zebra Case (Dretske 1970).

The methodology and assumptions of Weinberg, Nichols and Stich's studies have been widely criticized (Ludwig 2007; Kaupinnen 2007; Cullen 2010; Cappelen 2012; Woolfolk 2013; Deutsch 2010, 2015). However, leaving the metaphilosophical aspects of these studies aside, they opened the dispute on the (in)stability of epistemic intuitions. Since WNS's study, there have been plenty of other studies regarding cultural differences in epistemic intuitions elicited by Gettier-style scenarios (e.g. Machery et al. 2017a; Machery et al. 2017b) and the possible influence of various factors on epistemic intuitions, e.g. age (Colaço et al. 2014), gender (Buckwalter and Stich 2014) or personality (Machery 2017). There have also been several attempts to corroborate WNS's results (Nagel et al. 2013; Seyedsayamdost 2015; Kim and Yuan 2015). None of these succeeded, which means that there are no confirmed cultural differences in epistemic intuitions in almost all ${ }^{1}$ the cases studied by WNS. In this paper, we present evidence of cultural differences between Indians and Westerners in intuitions elicited by Dretske's Zebra Case. We also attempt to explain the effect we observed. Our explanation rests on the observation that the Zebra scenario is different from classic Gettier cases, since the former concerns skeptical pressure regarding perception, while the latter do not. We present some sociological and anthropological observations regarding the presence and importance of skepticism in Western culture, and the smaller importance and influence of skepticism regarding perception in Indian culture. An effort to confirm WNS's results regarding the differences between Indians' and Westerners' intuitions elicited by the Zebra Case fits in recent projects which aim to corroborate findings from classic studies in experimental philosophy. The problems with corroboration of various empirical projects have recently been increasingly raised. For this reason, the need for replications of results from experimental philosophy is frequently brought up (for the literature on the replication crisis in sciences other than experimental philosophy see e.g.: Ioannidis 2005; Chang and Li 2015; Open Science Collaboration 2015; Baker 2016; Miłkowski et al. 2018;

\footnotetext{
1 Seyedsayamdost failed to show differences between East Asians and Westerners in epistemic intuitions elicited by Truetemp Cases (inspired by Lehrer 1990), the Gettier Car Case (inspired by Gettier 1963), the Conspiracy Case (WNS's own case), and the Zebra Case. Seyedsayamdost also failed to show differences between South Asians (Indians) and Westerners in epistemic intuitions elicited by Truetemp Cases, the Getter Car Case, and the Conspiracy Case.
} 
for attempts to corroborate some classic X-Phi results see e.g.: Rose et al. 2017; Machery et al. 2020; van Dongen et al. 2020; Ziółkowski 2021; Cova et al. 2021; for methodological considerations concerning replication studies see Machery, 2020). The first large-scale replication project in experimental philosophy carried out by Cova et al. (2021) reran 40 X-Phi studies and, interestingly, the researchers found that demographic (including cross-cultural) effects were less likely to be corroborated than content-based effects (i.e. effects that result from manipulating the contents of the experimental materials). Our study can be seen as a contribution to the replicability project in experimental philosophy.

The structure of the paper is as follows. In Sect. 2, we review the methodological critique formulated against WNS's studies and show the reasons to expect differences between Indians and Westerners in intuitions regarding the Zebra Case. In Sect. 3, we describe our empirical protocol and methods, and we report our findings. In Sect. 4, we provide some arguments for the claim that the Zebra Case differs from paradigmatic Gettier cases in terms of its connection to skeptical pressure. In Sect. 5, we examine the presence and influence of skepticism in Western and Indian cultures. Section 6 is devoted to the range of possible metaphilosophical consequences of our findings. Finally, in Sect. 7, we draw final conclusions from our research.

\section{Reasons to Expect Cross-Cultural Differences in Epistemic Intuitions}

In his recent meta-analysis of experimental philosophy's empirical findings (2017: 54), Machery claims that Seyedsayamdost failed to confirm all the results WNS reported. Nevertheless, Seyedsayamdost himself explicitly reports that in the Zebra Case (for the precise formulation of the scenario, see Sect. 3.1), the data collected by him was insufficient to draw any conclusions about the purported differences between Indians and Americans (see the footnote in Seyedsayamdost 2015: 105). Therefore, Seyedsayamdost's failure to detect cross-cultural differences concerns all but one of the results of WNS: the differences between Indians and Westerners in epistemic intuitions elicited by the Zebra Case.

WNS's paper is one of the most influential articles in the field of experimental philosophy; however, it was criticized for its very small sample sizes and unrepresentative samples (the groups of Indians and East Asians were students living in the USA who self-identified as Indians or East Asians). Seyedsayamdost (2015), Nagel et al. (2013) and Kim and Yuan (2015) argued for replication because of these important methodological shortcomings of the original study. Importantly, all the attempts to corroborate WNS's results mentioned above were unsuccessful, while one of WNS's experiments has not yet been properly replicated. We find these reasons sufficient to justify the importance of undertaking this replication of WNS's experiment regarding the Zebra Case.

However, although all the past attempts to confirm WNS's findings failed, there are reasons to expect differences between Indians and Westerners regarding the Zebra Case. These reasons come from another study concerning differences 
in sensitivity to skeptical pressure between participants from India, China and the USA (Waterman et al. 2018) (for our arguments that the Zebra Case is a skeptical pressure case, but not a typical Gettier case, see Sect. 4.). Waterman et al. presented participants with vignettes that were similar to the original Zebra Case. Unlike in the WNS's experiments, the participants were asked to agree or disagree with a knowledge ascription to the protagonist on a 6-point Likert scale. One of Waterman et al.'s studies included two conditions: in one condition, the vignette was constructed in such a way that the possibility of error was increased; however, in the second condition it was not. For example, below are two versions of the vignette used by Waterman et al. which is the closest counterpart of the original Zebra Case:

Zoo Case, Normal Version: John and his friend go to the zoo. As they walk around, they pause in front of an exhibit marked "Brazilian Jaguar Enclosure." John and his friend read about jaguars from the sign, and look out and see a jaguar sleeping on the branch of a tree in the enclosure.

Zoo Case, Skeptical Version: John and his friend go to the zoo. As they walk around, they pause in front of an exhibit marked "Brazilian Jaguar Enclosure." John and his friend read about jaguars from the sign, and look out and see a jaguar sleeping on the branch of a tree in the enclosure. However, African leopards look very much like Brazilian jaguars, and the signs in the zoo have recently been replaced by an inexperienced crew of workers. If a zoo official had accidentally switched the signs on their exhibits, John wouldn't have been able to tell the difference between the jaguar he did see and a leopard. (Waterman et al. 2018: 192-193)

Waterman et al. found that American and Chinese participants were far more likely to give different knowledge ratings in the skeptical and normal version of the case presented above (and other similar cases) than Indians. It is especially important for us that the effect size for Americans was much bigger $(d=1.43)$ than for Indians $(d=0.6)$. While the vignettes used in the study were modeled after Dretske's Zebra Case, these results could suggest that there might be differences between Indians' and Americans' epistemic intuitions in ascribing knowledge in the original scenario.

The search for cultural differences is all the more important since much discussion on the reliability of epistemological methodology concerns the variability or stability of epistemic intuitions across cultures (for a systematic review of empirical literature which suggests that philosophical intuitions vary across cultures, see Machery et al. 2021; for opposite arguments, see Knobe 2019, forthcoming).

In summary, there is a need to fill the gap in the literature concerning replications of WNS's experiments by conducting a study regarding the differences between Indians and Westerners in the case of Dretske's Zebra Case. Moreover, the results presented by Waterman et al. seem to suggest that, in contrast to other effects reported by WNS, there are reasons to expect differences between Indians and Westerners that are in line with WNS's findings concerning the Zebra Case. In the next section, we discuss in detail our study, which aims to determine whether Westerners' intuitions about the Zebra Case differ from Indians'. 


\section{The Experiment}

\subsection{Methods, Materials and Procedure}

Our aim was to carry out a high-powered, pre-registered study that would mitigate the shortcomings of WNS's original experiment. Every important methodological aspect of the study was registered in advance (the pre-registration form can be found on the Open Science Framework webpage: https://osf.io/sypqg/).

Since WNS adopted a questionable method of identifying the ethnicity of their subjects, we employed a more sophisticated procedure based on that used by Seyedsayamdost (2015) in his replications of WNS's other experiments. The sample of Indians consisted of subjects who were located in India and self-identified as Indians; we excluded those who were not born on the Indian Subcontinent or had more than one grandparent or parent who was not born there. The group of Westerners consisted of subjects who resided in the USA and self-identified as "White/Caucasian"; we excluded those who (a) specified that their primary region was Eastern Europe or Middle East, (b) were born outside Western Europe or North America, or (c) had more than one grandparent or parent who was born outside Western Europe or North America. $^{2}$

The study was conducted online and designed with LimeSurvey (an open-source application for managing online surveys: www.limesurvey.org); the participants were recruited via Amazon MTurk. The survey language was English (similarly to the WNS's study and the replications carried out by Seyedsayamdost 2015). The first part of the survey contained the demographic questions: participants were asked about their age, gender, country of residence, country of origin, their native languages (each participant could specify more than one), and the places of birth of their parents and grandparents. Then, every respondent was presented with the Zebra Case (phrased exactly as in the original study by WNS) and asked the target question: Does Mike really know that the animal is a zebra, or does he only believe that it is? As in the original study, the answer format was binary: the participants were offered a choice between "Really knows" (knowledge attribution) and "Only believes" (knowledge denial). Here is the exact formulation of the vignette:

Mike is a young man visiting the zoo with his son, and when they come to the zebra cage, Mike points to the animal and says, "that's a zebra." Mike is right - it is a zebra. However, as the older people in his community know, there are lots of ways that people can be tricked into believing things that aren't true. Indeed, the older people in the community know that it's possible that zoo authorities could cleverly disguise mules to look just like zebras, and people viewing the animals would not be able to tell the difference. If the animal that Mike called a zebra had really been such a cleverly painted mule, Mike still

\footnotetext{
${ }^{2}$ We are aware that including only people who reside in the USA in the group of Westerners might be controversial; however, it is in line with the methodology adopted by WNS.
} 
would have thought that it was a zebra. Does Mike really know that the animal is a zebra, or does he only believe that it is?

In order to ensure high data quality, we employed a demanding attention check that was presented at the very end of the survey. Each subject was presented with the following text:

In order to facilitate our research, we are interested in knowing certain facts about you. Specifically, we are interested in whether you take time to read directions; if not, then the data we collect based on your responses will be invalid. So, in order to demonstrate that you have read the instructions, please ignore the next question (i.e., don't answer it), and simply write "I have read the instructions" in the box labeled "Please enter your comment here". Thank you very much.

Subjects could either answer the question Have you attended university? [yes/no] or leave the question unanswered and type "I have read the instructions" in the provided text field. Only those participants that provided the correct phrase in the text field were included in the final data analysis.In our pre-registration, we assumed we would need to achieve $90 \%$ power to detect a difference between ethnic groups of 15 percentage points in the proportions of knowledge attributions (one-tailed z-test). ${ }^{3}$ This means we needed at least 185 valid responses (i.e. not excluded by our demographic criteria or the attention check) in each demographic group.

\subsection{Participants}

All subjects were recruited via Amazon MTurk and received a small financial compensation for their participation in the study. For each sample, we set a different location request: all of the participants in the Indian sample had to be located in India, while for the sample of Westerners the location had to be the USA. The initial sample size was $N=729$ (379 respondents from the USA and 350 subjects from India), but a significant number of participants were excluded by our strict demographic criteria and the attention check (for details, see the section above), which yielded a final sample size of $N=415$ (204 Indians and 211 Westerners). Therefore, our sample size was sufficient to achieve the level of statistical power we assumed in the pre-registration. The average age of the respondents was 36.88 years $(S D=12.53) ; 36.4 \%$ were female $(63.4 \%$ declared as male and one participant chose the 'other' option).

\subsection{Results}

We performed a simple z-test (one-tailed, due to the directional hypothesis we tested) on the data we collected in order to compare the proportion of knowledge

\footnotetext{
${ }^{3}$ For calculations, we assumed the difference between proportions that requires the largest number of participants to be detected (50\% vs. $65 \%$ or $35 \%)$.
} 


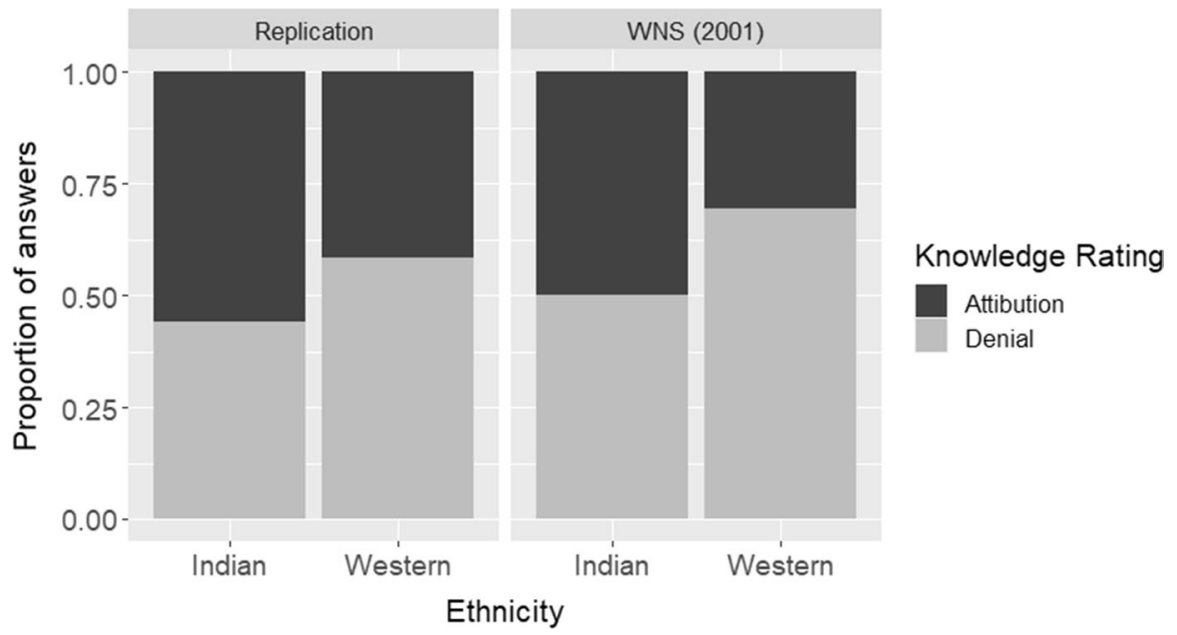

Fig. 1 The proportion of knowledge attributions and knowledge denials elicited by the Zebra Case among Westerners and Indians; the original WNS's study $(\mathrm{N}=86)$ vs. our Replication $(\mathrm{N}=415)$

attributions in the group of Indians and Westerners. The analysis found a significant difference between the ethnic groups in question: the Indians were more likely to ascribe knowledge in the Zebra Case (55.9\% of positive judgments) than the Westerners (only $41.7 \%$ of positive judgments): $z=2.89 ; p=0.002 ; \Phi=0.14$. Thus, our data did confirm the hypothesis regarding differences in Zebra Case intuitions between Westerners and subjects originating from the Indian Subcontinent, and the effect we found fits the predicted direction (the dataset can be accessed online via Open Science Framework webpage: https://osf.io/d9eg6/). The main analysis includes Indian subjects who fit our demographic criteria and passed the attention check but did not report English as their native language $(n=76)$. However, in the remaining sample of Indians who are native English speakers $(n=128)$, the proportion of knowledge attributions is similar as in the whole sample $(61.7 \%)$, so the cross-cultural effect persists and is even slightly more pronounced $(z=3.57$; $p<0.001 ; \Phi=0.19$ ). This provides further evidence to believe that the effect we observed is robust. The figure below illustrates our results and compares them to the results reported by the authors of the original WNS's study (Fig. 1).

It is worth noting, however, that the size of the effect we observed is not very large $(\Phi=0.14)$ and that the judgments provided by the participants in each group are highly divergent (close to a 50/50 distribution). One cannot say that positive or negative knowledge ratings strongly predominated in either of the ethnic groups we investigated. 


\section{What kind of case is the Zebra Case?}

Researchers have put much effort into finding cross-cultural variation (or uniformity) in intuitions regarding Gettier cases as they are purported counterexamples to the classic theory of knowledge (i.e. cases of justified true belief that should not be classified as knowledge), therefore they are extremely important for epistemology. Before we proceed with our explanation of the data we collected, we would like to stress that the Zebra Case, although it involves intuitions about knowledge, is very different from regular Gettier cases (we will even suggest that it is not a Gettier case at all).

In order to show that the Zebra Case does not have the typical traits of Gettier cases, we will use the framework offered by Blouw et al. (2017), which aims to provide a taxonomy of Gettier-style cases. It tracks differences between scenarios along three dimensions: Detection, Threat, and Replacement. Detection concerns whether or not an agent initially succeeds or fails to detect the truth value of the believed proposition; it is useful in drawing a distinction between so-called false lemma cases (where an agent arrives at a true conclusion on the basis of valid reasoning from at least one false premise, which was the main idea behind Gettier's original scenarios) and more sophisticated cases that do not involve reasoning from false premises (such as the Fake Barns scenario, see Goldman 1976). Clearly, the Zebra Case is not a false lemma case, which makes it much different from the original Gettier cases. Threat tracks the presence of epistemic misfortune and luck: one can form a true belief that might be, but is not, disrupted by misfortune (threat is unsuccessful), or a true belief whose truth-making relation ends up being disrupted by a stroke of bad luck (threat is successful). For example, if the protagonist in the Zebra Case was looking at the only real zebra in a flock of cleverly painted mules, then it would be a case of unsuccessful threat (the protagonist might have looked at a mule and formed a false belief, but the protagonist was lucky to have looked at the real zebra). However, such a threat is not present in the situation described in the Zebra Case we tested because the possibility of disguising mules as zebras is only mentioned in the story and is very remote for the subject in question. Replacement concerns cases in which Threat is successful, but thanks to another stroke of (good) luck the truthmaker of the belief in question is replaced in the process: the replacement might be very similar or quite dissimilar to the original truthmaker. Since there is no threat in the Zebra Case, there is no replacement either. It seems then that the Zebra Case does not possess any features that are crucial for it to be classified as a Gettier case.

We believe that all the dimensions listed by Blouw et al. (2017) are in fact different instances of epistemic luck, which is often said to play an important role in Gettier cases. We do not want to go into detail here, so, to put it briefly, epistemic luck occurs when highly unlikely events or circumstances affect the truth value of a belief $B$ held by a certain agent $A ; e$.g. a stroke of good luck $L$ makes $B$ true, but if $L$ had not occurred (which might have easily happened), B would be false and $A$ would still believe $B$. (for more precise attempts at defining epistemic luck see, for example, Pritchard 2004). In false lemma cases, agents are lucky to draw a true conclusion from false premises (they might have easily drawn a false conclusion instead); 
in unsuccessful threat cases, they are lucky that the epistemic threat does not succeed in making their crucial belief false; in replacement scenarios, there is a double stroke of luck: first, the truthmaker of the belief in question is removed (bad luck), but then it is sufficiently replaced so that the belief is still true (good luck). Again, in the Zebra Case we cannot find any presence of a similar sort of epistemic luck; bad luck is only mentioned as a far-fetched possibility.

So, what kind of case is the Zebra Case? We believe that the appropriate category here is skeptical pressure cases (for other examples of such vignettes, see Nagel et al., 2013). In these cases, the protagonist's belief is not true as a result of luck, but the reader is reminded of the possibility that the protagonist could be mistaken, even if that possibility is tiny or non-existent. In Gettier-style cases, where epistemic luck disrupts knowledge acquisition, a highly improbable stroke of good epistemic luck makes a certain belief true which would otherwise be false (thus, the belief is true by luck). In skeptical pressure cases the situation is, in a way, reverse: such stories only mention the remote possibility of an improbable stroke of bad epistemic luck that would make the belief in question false, if it had occurred; but since luck is not actually present, the belief is true not thanks to luck but due to reliable knowledge acquisition mechanisms.

The standard way of reminding the reader about such a possibility is to stress that the protagonist could be wrong since they cannot be certain that their belief is not false. For instance, in the Zebra Case it is explicitly stated that if the animal that Mike called a zebra had really been such a cleverly painted mule, Mike still would have thought that it was a zebra. Therefore, although Mike could believe that the animal in front of him is a zebra, he could be wrong since that animal could be a mule. Such a strategy of exerting skeptical pressure is based on the epistemic closure principle, which states that if $S$ knows that $p$ and $S$ knows that $p$ entails $q$, then $S$ knows that $q$. Let us use this principle on the Zebra Case. According to this principle, if Mike knows that the animal he is seeing is a zebra, and he knows that if that animal is a zebra then it is not a mule, then Mike knows that the animal he is seeing is not a mule. However, in the Zebra Case we are reminded that Mike cannot be certain whether the animal he is seeing is not a mule. Therefore, by modus tollendo tollens, which states that, if $p$ entails $q$ and $q$ is false, then $p$ is false, one could argue that Mike does not know that the animal he is seeing is a Zebra.

According to Dretske, one could argue that Mike does not know that the animal in front of him is a zebra only if one accepts the epistemic closure principle. Subsequently, one should agree that just the possibility - even if it is not actually present - of being misguided about the logical consequences of a given belief could be a reason to assume that a given belief is not knowledge. Note that such an argument is nothing more or less than an explication of the classic skeptical doubt, according to which just the possibility of a mistake undermines knowledge. Importantly, this is the case only in skeptical pressure cases but not in standard Gettier cases. As was previously mentioned, in Gettier cases the possibility of error is actually present (see Vogel 1990; Hawthorne 2004; Nagel et al. 2013).

However, a case was used in both WNS's and Seyedsaysmdost's studies which is not a classic Gettier case but also differs from the Zebra Case (and thereby from classic skeptical pressure cases). This case is the Conspiracy Case, in which the 
protagonist is aware of evidence according to which using nicotine without smoking does not increase the risk of getting cancer; however, the protagonist is also aware that the evidence could have been made up by the tobacco industry in order to increase tobacco companies' income.

There are at least three important differences between the Zebra Case and the Conspiracy Case. Firstly, the Conspiracy Case concerns testimonial knowledge, while the Zebra Case concerns perceptual knowledge. Secondly, in the Zebra Case the possibility of a mistake is much more related to classic skeptical doubts, i.e. doubts concerning the reliability of our perception; on the other hand, in the Conspiracy Case the doubts concern the reliability of scientific evidence and the impact of lobby groups on information provided to the public. Thirdly, note that the possibility that zoo authorities are disguising zebras in order to misguide zoo visitors is much stranger than the possibility that tobacco companies made up and publicized evidence that using nicotine does not increase the likelihood of cancer in order to increase their income.

Therefore, we claim that the major difference between the Zebra Case and other cases studied by WNS and Seyedsayamost is that doubts about whether the protagonist knows that $p$ in the Zebra Case results from skeptical pressure regarding perception, while in the other cases it could follow from other reasons, such as luck in being correct about $p$ or other features discussed above. This is a reason to assume that intuitions elicited only by the Zebra Case (among these studied by WNS) are related to its similarity to standard skeptical arguments or, more generally, to standard skeptical tropes.

\section{Indian culture is less skeptical than Western culture}

Our explanation of the results relies on the observed difference between the influence of skeptical tropes in Western and Indian cultures. We claim that while skepticism has a huge and important influence on both Western philosophy and culture, in Indian culture its presence is much smaller. Moreover, realist rather than skeptical tropes are widely present in Indian philosophy.

In the following sections, we present some evidence in favor of such claims. In Sect. 5.1 we discuss the presence of skeptical thought throughout the whole history of Western philosophy, and the manifestation of skeptical tropes in popular culture. Our aim is not to provide an exhaustive overview of the whole history of skepticism in Western philosophy but to demonstrate that in every stage of the evolution of Western thought, skepticism has played an important role. In Sect. 5.2 we discuss the body of evidence showing that skepticism regarding perception has played a much less important role in India than in the West. Therefore, we believe that the more vivid presence of skeptical tropes regarding perception in Western than in Indian culture could explain our results. What differentiates the intuitions elicited by skeptical pressure cases from those elicited by traditional Gettier-style cases is essentially the subjects' willingness to question the general reliability of a given mechanism of knowledge formation (be 
it testimony, analogy, or perception), not its applicability in superficially unfortunate circumstances (as in original Gettier or Fake Barn cases). The exposure to the arguments and tropes which question the reliability of perception may be therefore crucial in explaining our subjects' willingness to deny ascribing knowledge to the protagonist of our scenario.

\subsection{Skepticism in Western Culture}

Skepticism has been present and influential in the whole history of Western philosophy. In Ancient Greece, the best-known representatives of skepticism are, of course, representatives of the skeptic school, who argue that since we have no reasons to think that we can know anything for sure, we should practice epoche: in other words, we try to suspend all judgments. ${ }^{4}$

However, although Pyrrho and the skeptical school he established are usually considered the beginning of skeptical thought in Western philosophy, there had already been some skeptical threads before then. According to Lesher (1978), Xenophanes could be seen as the first regular skeptic among Western thinkers, since he insisted that "no human being knows; for even if by chance he should hit upon it, still he knows not that he has hit upon it but imagines and opines" (Lesher 1978: 1). Although - according to a more recent interpretation of Xenophanes - this phrase should not be interpreted as an expression of global skepticism, it at least expresses skepticism towards direct perception (Lesher 2019). As well as those in the works of Xenophanes, some skeptical tropes also appear in the thought of Parmenides, Heraclitus and Democritus (Lee 2001).

An example of an extremely influential skeptical trope in ancient Greece after Pyrrho is Plato's Cave (Republic: 514a-520a); this very famous philosophical thought experiment concerns the possibility of being misled by perception. This skeptical trope is important for all of Plato's epistemology, according to which our knowledge does not stem from perceiving things but rather from recollecting truths about ideas by anamnesis.

Skepticism did not disappear after the end of the ancient era; it was still influential in the middle ages: both as a defended view which aimed to contrast the limitations of human knowledge with God's omniscience (such a view was defended by, e.g., Lactatius (2007), and John of Salisbury (see: Lagerlund 2010: 10)); and as a criticized view (one of the most important critics of skepticism was Augustine of Hippo, who argued for unquestionable content of mind and for the theory of

\footnotetext{
${ }^{4}$ One could argue that the answer options given to the participants in our study ('only believes' or 'really knows') do not include the Pyrrhonian option, i.e. the attitude to "suspend all judgments". Unfortunately, offering a third, Pyrrhonian option to the respondents would be a serious methodological deviation from the original study which we wanted to replicate as closely as possible. Moreover, although the option 'only believes' does not perfectly reflect the suspension of judgment, we believe that, lacking other appropriate answer options, the respondents who would like to express their Pyrrhonian attitude would still choose 'only believes' rather than 'really knows' (since the latter carries definitely more epistemic weight than the former, to put it figuratively). We are grateful to an anonymous reviewer (this journal) for drawing our attention to this issue.
} 
illumination, which aimed to provide infallible ground for knowledge (Augustine: Contra Academicos)).

While skeptical tropes in the middle ages appeared mainly as a result of criticism of skepticism, it is undoubtedly true that Cartesian skepticism should be seen as modern philosophy's foundational thought. The Cartesian skeptical arguments presented in his Meditations (Descartes 1641 [1931]) regarding the possibility of being permanently deceived about the existence of the external world involve the aforementioned closure principle (see DeRose and Warfield 1999). Let us remember that the Zebra Case was presented in Dretske's article in order to discuss this principle. While this issue, which concerns the Zebra Case and which is supposed to be intuitive, has its roots in the thought of one of the most famous, well known and influential European philosophers, it seems to be unsurprising that people familiar with Cartesian doubts would be very susceptible to skeptical pressure.

Enough about the history of philosophy, and let us not discuss examples of skeptical tropes in contemporary philosophy in detail (the most obvious examples of influential works that argue for or against some sorts of skepticism are Ayer 1940; Moore 1939; Wittgenstein 1969; Putnam 1981). Note that in Western (pop)culture, skeptical themes appear quite often. The Matrix 5 or Inception are notable examples of movies that discuss the skeptical hypothesis concerning the existence of the external world. Moreover, both these movies not only discuss the possibility that the external world does not exist. In both of them, this possibility turns out to be partly true. Note that these movies do not aim to be pop-science products for educational purposes. These are mainstream, award-winning, popular movies. Therefore it seems plausible that the philosophical ideas raised by these movies were already widely known, or at least became known after the peak of these movies' popularity.

These movies are not exceptions. In addition to The Matrix and Inception, there are plenty of other examples of books or movies that contain skeptical tropes, such as The Truman Show, Simulacron-3, The Thirteenth Floor, ${ }^{6}$ Solaris $^{7}$ or Midnight in Paris.

In sum, skeptical thought, especially regarding the (un)reliability of perceptual knowledge, has been present and influential throughout the whole history of Western philosophy. For modern philosophy, because of Cartesian skeptical arguments, skepticism took the leading role. Nowadays, there are plenty of examples of skeptical tropes not only in philosophy but also in popular culture. These insights are not new or surprising; however, what might be considered striking is the difference between the importance of skepticism in Western culture and in Indian culture. In the next section, we will discuss the role of skepticism in Indian culture and argue that its importance was rather small in contrast to Western culture.

\footnotetext{
5 For a more detailed discussion on the philosophical, and especially skeptical tropes in The Matrix see e.g. Chalmers 2005 .

6 Which was loosely based on the book Simulacron-3.

7 Both the novel by Lem and the two movies based on it: one directed by Tarkovsky (1972) and one directed by Soderbergh (2002).
} 


\subsection{The lack of skepticism in Indian culture}

Although it is an impossible task to demonstrate the absence of certain skeptical tropes in Indian culture, we believe that there exists a body of evidence showing that skepticism regarding perception is not as prominent in India as in the West. An interesting point may be raised by studying the history of Indian philosophical tradition and the presence of skeptical tropes regarding perception. In comparison to Western and other philosophical traditions, the lack of such tropes may amount to an explanation of the stronger prevalence of knowledge attributions in the Zebra Case among Indian subjects.

Chatterjee (1977) in his assessment of the history of skepticism in Indian philosophy, Dipankar Chatterjee notes that "the Indian philosophical tradition lacks a thorough system of skepticism" (1977: 195), in the sense in which skepticism is understood as the position that there are no justifiable knowledge claims (1977: 195-196). This understanding is, of course, very narrow and probably can only be attributed to Pyrrhonian skeptics; significantly, however, most of the different skeptical tropes encountered in Indian philosophy do not include skepticism about perception. Nyāya, a central epistemological school of the classic period of Indian philosophy, takes perception (pratyaksa) to be one of the four legitimate means of knowledge (pramāna), along with inference (аnumāna), analogy (upamāna) and testimony (śabda). Although the last three have been contested as improper by various epistemological schools, even the Carvaka, a radical materialist school (probably most deserving of the term "skeptical"), famously held that sense-perception is the only proper way of knowing. A renewed interest in Classic Indian skepticism resulted in the interpretations of the 8-9th-century philosopher Jayarăśi (see Mills 2015; Balcerowicz 2020). These interpretations portray Jayarāśi as a radical skeptic who explicitly engages with $N y \bar{a} y a$ and Carvaka traditions ${ }^{8}$ and also denies pratyakșa the status of pramāna. However, Jayarâśi's conclusions seem to be widely criticized in classic Indian philosophy and are not seen as a major threat to philosophical analysis of perception. If we agree that the prevailing position in Indian philosophical analysis of perception was that of Nyāya's "direct realism" (Matilal 1986: 223-224), then its contrast with the Western philosophical tradition - which has been troubled with questions of the reliability of sense-perception since antiquity - becomes clearly visible. It is therefore possible that the cultures that gave birth to and were influenced by these considerations significantly differ in terms of their attitudes towards perceptual knowledge, which might explain the differences we observed.

This observation does not generalize further onto other skeptical problems: although WNS claimed that South Asians are also more eager to ascribe knowledge in Gettier cases, the subsequent replication failed to confirm this result

\footnotetext{
${ }^{8}$ Buddhist philosophers Nagarjuna and Vasubandhu also seem to be notable exceptions to Chatterjee's claim. However, their skeptical projects tend to acknowledge perception as a valid source of knowledge in at least some readings (as well as later developments in the Indian Buddhist epistemological tradition following Dignaga), and they definitely focus more on Buddhist skepticism towards the notion of "the self" or "reality".
} 
(Seyedsayamdost 2015). This is in line with the observation that general epistemological considerations concerning the definition of knowledge are deeply rooted in Indian philosophical tradition, with 12th-century philosopher Śrīharșa even formulating four cases that bear a striking resemblance to Gettier cases - as has been discussed by Nyāya philosophers (most notably Gañgeśa, see: Matilal 1986: 135-140, Ganeri 2018: 16-19).

It is also noteworthy that both Weinberg et al. (2001) and Seyedsayamdost (2015) found no cross-cultural differences with regards to knowledge ascription in the Zebra Case among Westerners and East Asians (Chinese subjects). Interestingly, perception-related skeptical positions may be easily found in Chinese philosophy in the impactful texts of Laozi (see Cheng 1977) and Zhuangzi, who famously presented a "Butterfly Dream" argument bearing striking similarities with Descartes's "Evil Demon" hypothesis. The influence of Buddhist skepticism on Chinese philosophical culture was significant (Guang 2013), which may have also contributed to the overall presence of skepticism regarding perception. This observation further corroborates the hypothesized connection between the presence of certain philosophical ideas in culture and the philosophical intuitions shared by its living community.

We believe that it is probable that certain philosophical positions and tropes (such as Western rationalist distrust of perception as a source of knowledge) simply did not influence the subjects who attributed knowledge to the protagonist in the Zebra Case in our study. It could also be the case that a deeper absence of skeptical considerations in religious or social traditions influenced both India's philosophical landscape and modern culture. The absence of these motifs in Indian culture and education might explain the higher prevalence of intuitions supporting knowledge attribution among subjects from India, as opposed to their wider presence in Western and Chinese culture. This also parallels the size of our effect: a more visible and influential presence of skeptical intuitions regarding perception probably did not influence all Westerners or East Asians, while some Indians were still exposed to them. Therefore, the difference in knowledge attribution between Western and Indian culture is significant, but it is not an allor-nothing phenomenon.

These considerations of course should come with a caveat: relying on philosophy as evidence for the lack of skeptical tropes in culture in order to substantiate the laypersons' lack of skeptical intuitions should be approached carefully. We do not possess any evidence suggesting that a parallel lack of skeptical tropes occurs in pop-culture, education or science, apart from the lack of positive evidence suggesting otherwise. However, there are two points that may strengthen the treatment of philosophy as a pars pro toto in this case. Firstly, as noted in the above section, philosophy seems to be a primary source of many skeptical tropes in modern Western pop-culture. Although we did not find any thorough study of the presence of skeptical tropes in Indian pop-culture, we might expect that the lack of such tropes in philosophy should have at least a slight impact on their prevalence in broader culture. Secondly, the Classic Indian philosophy is rooted in India's religious traditions with continuous practice of commentary on the Vedas. It would be surprising if the tropes present in religion were not discussed in detail by philosophers. We 
might therefore expect the lack (or a scarce presence) of skeptical tropes occurring in religious circumstances or being discussed in religious contexts. These contexts probably have a much greater impact on laypersons' intuitions. That being said, we acknowledge that considerations offered in this section are speculative and are meant to open a discussion about the interpretation of this effect instead of offering an ultimate explanation.

\section{What these Results do (not) Show}

Does the size of the effect we observed allow us to draw any interesting philosophical conclusions? We believe that an answer to this question depends on one's theoretical approach towards experimental philosophy and philosophical interests. We will discuss the significance of these results regarding three crucial theoretical enterprises: the negative project of experimental philosophy (as defended, e.g., in Weinberg et al. 2001 and Nichols et al. 2003); the descriptive approach in experimental epistemology; and in cultural anthropology.

The original research project which inspired our study was Weinberg et al. (2001), which was actually one of the founding texts of the negative program in experimental philosophy; therefore, our result should be discussed in comparison with the theses advanced in this paradigm. In their report on their findings concerning the Zebra Case, WNS discuss this case in the following manner:

"What's going on in these last two [Zebra and Conspiracy] cases? Why do Scs [people from the Indian subcontinent] and Ws [Westerners] have different epistemic intuitions about them? The answer, to be quite frank, is that we are not sure how to explain these results. But, of course, for our polemical purposes, an explanatory hypothesis is not really essential. The mere fact that Ws, Eas [East Asians], and SCs have different epistemic intuitions is enough to make it plausible that IDR [Intuition-Driven Romanticism] strategies which take these intuitions as inputs would yield significantly different normative pronouncements as output". (Weinberg et al. 2001: 445).

In Nichols et al. (2003), the authors also link the existence of this effect to their broader skepticism about the universality of intuitions that are reflected in the study of knowledge attribution. They also discuss the results of WNS's experiments concerning the Zebra Case and the Conspiracy Case (Nichols et al. 2003: 15 ), which involves similar skeptical pressure regarding testimonial evidence (see Weinberg, Nichols, Stich: 444). The proponents of the negative program therefore use this data to support the thesis that the intercultural differences in philosophical intuitions render the use of intuitions in epistemology unjustified. "[T]he lesson to be drawn from our cross-cultural studies is that, however obvious they may seem, these [skeptical] intuitions are simply not to be trusted" (Nichols et al. 2003: 17).

However, even if IDR is a proper picture of an actual philosophical method (for arguments against that view see e.g. Williamson 2007; Deutsch 2010, 2015; Cappelen 2012), such explanations and conclusions would follow from our result 
only if we observed a kind of systematic difference in a variety of cases regarding knowledge attribution between subjects from different cultural backgrounds. In the light of negative replications of all WNS's other findings regarding differences in knowledge attributions between Westerners and Indians/East Asians (including the purported difference in the Conspiracy Case; see Seyedsayamdost 2015), we should also be skeptical of drawing such major conclusions from our study. We believe that our proposed explanation, which limits itself to pointing out differences in approaches to determining the legitimacy of perception as a means of knowledge between Indian and Western cultures, is much more modest and captures the crucial difference between the Zebra Case and other cases studied by WNS and Seyedsayamdost (2015). Compared to the scarce evidence of similar worries regarding perception, the widespread presence of skepticism towards testimonial evidence and Gettier-style cases in Indian philosophy may nicely illustrate our point and explain the peculiar difference in knowledge attribution in the Zebra Case but not in others. The fact that the difference in intuitions between Indians and Westerners exclusively concerns the Zebra Case also cannot be accounted for by the original suggestion made by WNS, i.e. that cultural differences in epistemic intuitions may have their roots in the different "thinking styles" or "belief-forming strategies" of subjects from different cultures, as postulated by Nisbett et al. (2001). ${ }^{9}$

It is also worth noting that the effect we observed, though robust and significant, is not overwhelming. The strongest claim that may be substantiated by our results is that the overall tendency among Western subjects to deny knowledge attribution in the Zebra Case does not prevail among subjects from the Indian subcontinent. Such a claim is not strong enough to substantiate the negative approach of WNS, but it is sufficiently interesting for cultural anthropologists and for epistemologists interested in the influence of culture on epistemic intuitions. If our explanation of the data is correct, then it may shed some light on anthropologically interesting differences between Western and Indian culture regarding the presence of certain ideas or tropes.

Before drawing final conclusions, let us point out some limitations of the explanation of the cross-cultural effect that we found. The main aim of this paper is to investigate cross-cultural differences between Indians and Westerners in their intuitions elicited by the Zebra Case. We would like to stress that our explanation, which rests on observations regarding the skeptical tropes in Indian and Western cultures,

\footnotetext{
${ }^{9}$ Apart from the exclusivity of the Zebra Case among other scenarios, it is also doubtful whether such a "Nisbettian" explanation may at all account for the described difference in epistemic intuitions between subjects from India and the USA. The opposition between "holistic" and "analytic" thinking styles described by Nisbett et al. (2001) applied exclusively to the difference between Western and East Asian culture (which do not differ with respect to the number of subjects who ascribe knowledge to the protagonist in the Zebra Case, as shown in both Weinberg, Nichols, Stich 2001 and Seyedsayamdost 2015). It is also rather unclear why knowledge ascription in the Zebra Case should be regarded as more "holistic" than the "analytic" option.
} 
should be seen as a suggestion - a plausible one, but still just a suggestion or an empirically testable hypothesis. Note that there are other possible explanations of our results - e.g. Indians could attribute knowledge in the Zebra Case less willingly than Westerners because Indians go to the Zoo less often but, on the other hand, see animals more often in the wild ${ }^{10}$; or because Indians are less familiar with mules and zebras than Westerners (or more familiar - we do not have any reasons to think that explanations just mentioned are plausible, however, they are possible). In order to rule out such alternative explanations, further studies should be conducted. We are aware of that fact, and therefore, as mentioned, we treat our explanation as a suggestion and as a plausible starting point for future studies on cross-cultural differences in epistemic intuitions between Indians and Westerners, which hopefully could either confirm or falsify our explanation.

Since, as we argue, the crucial feature which is responsible for differences between Westerners and Indians in our study is the lack or presence of skeptical tropes in these cultures while the Zebra Case encourages skeptical pressure, we believe that the possible follow up studies which could help to confirm our explanation would focus on similar cross-cultural differences in other skeptical pressure cases (e.g. these used by Nagel et al. (2013) in their studies; we quote these scenarios in the Appendix).

\section{Conclusion}

We believe that the conclusion of this paper should be regarded as threefold. Firstly, it fills the gap in the literature regarding WNS's studies of cross-cultural differences in the exhibition of skeptical intuitions. The Zebra Case stands out as the only experiment that has not been yet replicated, while the replications of other experiments performed by WNS that used more precise ethnic background criteria and tested more subjects than the original studies failed to corroborate WNS's findings. Our experiment used the exact same scenario as WNS but more rigorous ethnic group inclusion criteria than the original study; also, it was performed on significantly more subjects than the original experiment. The result, contrary to replications of other WNS's experiments, was positive: we observed a significant difference between subjects from the Indian subcontinent and Westerners in the expected direction, with $55.9 \%$ of the former and only $41.7 \%$ of the latter attributing knowledge to the protagonist in the Zebra Case. This result completes the task of replicating the findings of Weinberg et al. (2001).

The above-mentioned result brings us to the second conclusion of this paper, which is the specificity of the Zebra Case among the other scenarios tested by WNS. Our results call for an explanation of why a cross-cultural difference in knowledge attribution was observed in the Zebra Case but not in others. By analyzing the properties shared by the Gettier scenarios, we determined that the Zebra Case should be regarded as concerning skeptical pressure, not epistemic luck (which concerns

\footnotetext{
${ }^{10}$ We are grateful to an anonymous rReviewer for this journal for raising the possibility of alternative explanations of our results and for pointing out the limitations of our study.
} 
Gettier-style scenarios). Furthermore, by comparing it to the Conspiracy Case, which is similar, we singled out the crucial property of the Zebra Case, which is skeptical pressure concerning perceptual knowledge (unlike the Conspiracy Case, in which skeptical pressure applies to the reliability of testimony). Therefore, in light of all these observations, we argue that the difference between Indians and Westerners does not concern skeptical intuitions in general (as claimed by WNS); instead, it specifically concerns skeptical intuitions about the reliability of perception as a source of knowledge.

The third conclusion we draw is the possible explanation of the difference we found. We believe that the fact that subjects from India are more eager to attribute knowledge in the Zebra Case than Westerners may be elucidated by the presence of skeptical tropes concerning perception in culture and education. We compared the corpus of classical Indian and Western philosophy and found a crucial difference in the presence of skeptical arguments concerning the reliability of perceptual knowledge. Classical Indian philosophy is much more reluctant to deny perception the status of a reliable source of knowledge (as evidenced by the dominant tradition of Nyaya and critical points raised by other thinkers) than classical and modern Western philosophers. We also believe that the overall use of skeptical tropes in (pop) culture is much more present in Western media and education than in India. The peculiarity of Indian tradition may also be compared with classical Chinese philosophy, where skeptical doubts concerning perception were more widespread, which might also explain why the difference in knowledge attribution between Westerners and East Asians in the Zebra Case was not observed (Seyedsayamdost 2015).

We believe, therefore, that this study may close one chapter and open another. It concludes the nearly 20-year discussion concerning the robustness of the effects observed by Weinberg et al. (2001), but it also provides us with the prospect of benefits stemming from careful comparative study between different philosophical traditions. If our explanation of this effect is correct, then it is also possible that the general impact of philosophy on modern culture may run deep and vary across different cultures. In this sense, we believe it may inspire other empirical hypotheses concerning cross-cultural differences in philosophical intuitions.

\section{Appendix}

Skeptical pressure cases from Nagel et al. $2013^{11}$ :

1. Albert is in a furniture store with his wife. He is looking at a bright red table in a display. The displays in the showroom have been set up by a decorator who has a real flair for design. The showroom features a mix of contemporary and modern pieces. Albert likes the way this table looks, and starts to think about buying it. He believes the table is just the shade of red he was looking for. However, a white table under red lighting would look exactly the same to him, and Albert has not

$\overline{11 \mathrm{We} \text { are grateful to the authors }}$ of this study for providing their research materials on request. 
checked whether the lighting in this store is currently normal, or whether there might be a red spotlight shining on this particular table. There is in fact normal lighting throughout the showroom. Albert asks his wife, "Do you like this red table?"

2. Emma is shopping for jewelry. She goes into a nice-looking store, and spends some time looking at several different displays. She tells the salesperson that she is looking for a diamond necklace with a classic design. She always likes to try things on before she makes up her mind about them, and the salesperson shows her several options. Emma selects a diamond pendant from a tray marked "Diamond Earrings and Pendants". "What a lovely diamond!" she says as she tries it on. Emma could not tell the difference between a real diamond and a cubic zirconium fake just by looking or touching.

3. Amanda has just arrived at Atlantic University as a spring term transfer student. She is looking forward to the change of attending a different institution for a semester, although she knows she will be missing her friends. Today she has to run some errands, including buying a new battery for her laptop computer. After that, Amanda realizes she also needs to get a library card. It's a long walk from the computer store down to the library, but it is a nice day, and Amanda doesn't mind the walk. When she gets to the library, Amanda goes to the front information desk to ask where to get a card. There is no one staffing the desk just then, so she asks a passing student instead. The student tells her that campus ID cards, which also work as library cards, are issued at a booth on the ground floor of the student activity centre. This is in fact true, although Amanda has no special information on whether this student is trustworthy or well-informed. In any event, Amanda thanks the student and heads over to the student activity centre.

4. Wanda is out for a weekend afternoon walk near the train station and wonders what time it is. She glances up at the clock on the train station wall and sees that it says $4: 15 \mathrm{pm}$. It is in fact 4:15 pm at that moment. The station clock is in fact working, but it has no second hand, and Wanda only looks at it for a moment, so she would not be able to tell if the clock were stopped.

5. Luke works in an office with two other people, Victor and Monica. They all get along fairly well, chatting at the water cooler when work is slow. All winter Victor has been telling Luke about his plans to go to Las Vegas on his vacation, even showing Luke the website of the hotel where he has reservations. When Victor is away on vacation, Luke sees Victor's Facebook photos of himself with Vegas landmarks in the background, together with status updates about how much he is enjoying his trip. Victor really did have a good time in Vegas, and was sad to go back home to Markham. When he gets back to work, Victor talks a lot to Luke about how much fun he had on vacation. The resolution on the Facebook photos was low, however; Luke could not tell the difference between real vacation pictures from Las Vegas and fakes created with Photoshop.

6. Sarah is out with some friends, shopping for clothing at a large mall. She and her friends spend quite a bit of time hanging out at the mall trying things on and discussing fashion. As Sarah is standing at the entrance of her favorite store, she sees someone being chased by several security guards. "Oh my God!" she exclaims. "I recognize him. It's Walter, this guy I worked with as a lifeguard last summer." 
The guards catch up and put Walter into handcuffs right in front of Sarah and her friends. Sarah got a good look at Walter there, but would not have been able to tell him apart from his twin brother, if he had a twin brother (he doesn't actually have one).

7. Paul Jones was worried because it was $10 \mathrm{pm}$ and his wife Mary was not home from work yet. Usually she is home by $6 \mathrm{pm}$. He tried her cell phone but he just kept getting her voicemail. Starting to worry that something might have happened to her, he decided to call around to local hospitals to ask whether any patient by the name of "Mary Jones" had been admitted that evening. The switchboard operator of the county hospital confirmed that someone by that name had been admitted with major but not life-threatening injuries following a car crash. Paul's wife was in fact awaiting surgery in the hospital at that moment. Paul did not stop to wonder how reliable the switchboard operator would be, or whether she might be referring to another person with the same name as his wife. He just grabbed his coat and rushed out to the county hospital.

8. Brad is driving up to his cousin's cottage north of the city with some friends of his. It is late Friday afternoon, and it's sunny and clear out. Brad and his friends are even enjoying the long drive. At one bend in the road Brad points at something on the side of the road. "Hey, look - it's a baby deer!" Everyone in the car sees what Brad does, and agrees that there's a very cute baby deer standing very still in the fenced field by the side of the road. The deer doesn't move as they watch it. At this distance they would not have been able to tell if it had been just a realistic statue rather than a real deer, but it is in fact a real deer, just as they thought. They slow down to take a good look, and then keep on driving.

Acknowledgements We would like to thank Edouard Machery, Vilius Dranseika, Kevin Reuter, Baljeet Singh Goraya and an anonymous reviewer for this journal for their feedback on earlier versions of the manuscript that led to its substantial improvement. We are grateful to Jacek Woźniak for his valuable suggestions regarding the Tamil and Sanskrit vocabulary describing knowledge. Finally, many thanks to Bartosz Maćkiewicz for his help on the survey's technical aspects. This work was funded by the Ministry of Science and Higher Education (Poland) research grant DI2017 001347 (PI: Krzysztof Sękowski) as part of the "Diamentowy Grant" and by the Faculty of Philosophy at the University of Warsaw (research subvention granted to Adrian Ziółkowski).

Open Access This article is licensed under a Creative Commons Attribution 4.0 International License, which permits use, sharing, adaptation, distribution and reproduction in any medium or format, as long as you give appropriate credit to the original author(s) and the source, provide a link to the Creative Commons licence, and indicate if changes were made. The images or other third party material in this article are included in the article's Creative Commons licence, unless indicated otherwise in a credit line to the material. If material is not included in the article's Creative Commons licence and your intended use is not permitted by statutory regulation or exceeds the permitted use, you will need to obtain permission directly from the copyright holder. To view a copy of this licence, visit http://creativecommons.org/licen ses/by/4.0/.

\section{References}

Ayer, Alfred Jules. 1940. The foundations of empirical knowledge. London: The MacMillan Press Ltd. Baker, Monya. 2016. Is there a reproducibility crisis? Nature 533 (1): 452-454. 
Balcerowicz, Piotr. 2020. Jayarāśi, The Stanford Encyclopedia of Philosophy (Winter 2020 Edition), ed. Edward N. Zalta , Retrieved April 5, 2021 from URL $=<$ https://plato.stanford.edu/archives/win20 20/entries/jayaraasi/>.

Blouw, Peter, Wesley Buckwalter, and John Turri. 2017. Gettier cases: A taxonomy. In Explaining knowledge: New essays on the Gettier problem, eds. Rodrigo Borges, Claudio de Almeida, Peter Klein, Oxford: Oxford University Press: 242-252.

Buckwalter, Wesley, and Stephen Stich. 2014. Gender and philosophical intuition. In Experimental Philosophy (Volume 2), eds. Joshua Knobe and Shaun Nichols, Oxford: Oxford University Press. https://doi.org/10.1093/acprof:osobl/9780199927418.001.0001.

Cappelen, Herman. 2012. Philosophy without intuitions. New York: Oxford University Press. https://doi. org/10.1093/acprof:oso/9780199644865.001.0001.

Chalmers, David. 2005. The Matrix as metaphysics, In Philosophers Explore the Matrix, ed. Chrispother Grau, Oxford: Oxford University Press.

Chatterjee, Dipankar. 1977. Skepticism and Indian philosophy. Philosophy East and West 27 (2): 195209. https://doi.org/10.2307/1397616.

Chang, Andrew C., and Phillip Li. 2015. Is economics research replicable? Sixty published papers from thirteen journals say "usually not”, Finance and Economics Discussion Series 2015-2083. Washington, DC: Board of Governors of the Federal Reserve System.

Cheng, Chung-Ying. 1977. Nature and function of skepticism in Chinese philosophy. Philosophy East and West 27 (2): 137-154. https://doi.org/10.2307/1397612.

Colaço, David, Wesley Buckwalter, Stephen Stich, and Edouard Machery. 2014. Epistemic intuitions in fake-barn thought experiments. Episteme 11 (2): 199-212. https://doi.org/10.1017/epi.2014.7.

Cova, Florian, et al. 2021. Estimating the reproducibility of experimental philosophy. Review of Philosophy and Psychology 12: 9-44 (2021). https://doi.org/10.1007/s13164-018-0400-9.

Cullen, Simon. 2010. Survey-driven romanticism. Review of Philosophy and Psychology 1 (2): 275-296. https://doi.org/10.1007/s13164-009-0016-1.

DeRose, Keith, and Ted A. Warfield. 1999. Skepticism: A contemporary reader. Oxford: Oxford University Press.

Descartes, Rene. 1641. Meditations on first philosophy. In Philosophical Works of Descartes. (Vol. 1), eds./trans. Elizabeth S. Haldane, G.R.T. Ross. New York: Dover Publications, 1931.

Deutsch, Max. 2010. Intuitions, counter-examples, and experimental philosophy. Review of Philosophy and Psychology 1 (3): 447-460. https://doi.org/10.1007/s13164-010-0033-0.

Deutsch, Max. 2015. The myth of the intuitive. Cambridge, MA: MIT Press.

Dretske, Fred I. 1970. Epistemic operators. The Journal of Philosophy 67 (24): 1007-1023. https://doi. org/10.2307/2024710.

Ganeri, Jonardon. 2018. Epistemology from a sanskritic point of view. In Epistemology for the Rest of the World, ed. Stephen Stich, Masaharu Mizumoto, and Eric McCready, 13-21. Oxford: Oxford University Press.

Gettier, Edmund. 1963. Is justified true belief knowledge? Analysis 23 (6): 121-123.

Goldman, Alvin. 1976. Discrimination and perceptual knowledge. Journal of Philosophy 73: 771-791. https://doi.org/10.2307/2025679.

Guang, Xing. 2013. Buddhist Impact on Chinese culture. Asian Philosophy: An International Journal of the Philosophical Traditions of the East 23 (4): 305-322. https://doi.org/10.1080/09552367.2013. 831606.

Hawthorne, John. 2004. Knowledge and Lotteries. Oxford: Oxford University Press.

Ioannidis, John P.A. 2005. Why most published research findings are false. PLoS Medicine 2 (8): e124. https://doi.org/10.1371/journal.pmed.0020124.

Kauppinen, Antti. 2007. The rise and fall of experimental philosophy. Philosophical Explorations 10 (2): 95-118. https://doi.org/10.1080/13869790701305871.

Kim, Minsun, Yuan Yuan. 2015. No cross-cultural differences in the Gettier car case intuition: A replication study of Weinberg et al. 2001. Episteme 12: 355-61.

Knobe, Joshua. 2019. Philosophical intuitions are surprisingly robust across demographic differences. Epistemology \& Philosophy of Science 56: 29-36. https://doi.org/10.5840/eps201956225.

Knobe, Joshua. forthcoming. Philosophical intuitions are surprisingly stable across both demographic groups and situations, Filozofia Nauki.

Lactantius. 2007. Divinae institutiones III-IV. eds. Eberhard Heck, Antonie Wlosok, Berlin: W. de Gruyter. 
Lagerlund Henrik. 2010. Rethinking the history of skepticism. The Missing Medieval Background. Leiden-Boston: Brill.

Lee, Richard. 2001. Being skeptical about skepticism: methodological themes concerning Ockham's alleged skepticism. Vivarium 39 (1): 13-35. https://doi.org/10.1163/15685340152882516.

Lehrer, Keith. 1990. Theory of knowledge. Nashville: Westview Press.

Lesher, James H. 1978. Xenophanes' scepticism. Phronesis 23 (1): 1-21. https://doi.org/10.1163/15685 2878 X00181.

Lesher John. 2019. Xenophanes. In. The stanford encyclopedia of philosophy (Summer 2019 Edition), ed. Edward N. Zalta, Retrieved April 5, 2021 from URL $=<$ https://plato.stanford.edu/archives/ sum2019/entries/xenophanes/>.

Ludwig, Kirk. 2007. The epistemology of thought experiments: First person versus third person approaches. Midwest Studies in Philosophy 31 (1): 128-159. https://doi.org/10.1111/j.1475-4975. 2007.00160.x.

Mills, Ethan. 2015. Jayarāśi's delightful destruction of epistemology. Philosophy East and West 65 (2): 498-541. https://doi.org/10.1353/pew.2015.0049.

Matilal, Bimal Krishna. 1986. Perception: An essay on classical Indian theories of knowledge. Oxford: Clarendon Press.

Machery, Edouard. 2017. Philosophy within its proper bounds. Oxford: Oxford University Press.

Machery, Edouard. 2020. What is a replication? Philosophy of Science 87 (4): 545-567.

Machery, Edouard, et al. 2017a. Gettier across cultures. Noûs 51 (3): 645-664. https://doi.org/10.1111/ nous. 12110 .

Machery, Edouard, et al. 2017b. The Gettier intuition from South America to Asia. Journal of Indian Council of Philosophical Research 34 (3): 517-541. https://doi.org/10.1007/s40961-017-0113-y.

Machery, Edouard, Christopher Grau, and Cynthia Pury. 2020. Love and power: Grau and Pury (2014) as a case study in the challenges of X-Phi replication. Review of Philosophy and Psychology 11: 995-1011.

Machery, Edouard, and Stephen Stich. 2021. Demographic differences in philosophical intuition: a reply to Joshua Knobe. The Review of Philosophy and Psychology.

Miłkowski, Marcin, Witold M. Hensel, and Mateusz Hohol. 2018. Replicability or reproducibility? On the replication crisis in computational neuroscience and sharing only relevant detail. Journal of Computational Neuroscience 45 (3): 163-172. https://doi.org/10.1007/s10827-018-0702-z.

Moore, George. 1939. Proof of an external world. In his Philosophical Papers, 144-8. New York: Collier Books.

Nagel, Jennifer, Valerie San Juan, and Raymond Mar. 2013. Lay denial of knowledge for justified true beliefs. Cognition, 129(3): 652-661. https://doi.org/10.1016/j.cognition.2013.02.008.

Nichols, Shaun, Stephen Stich, and Jonathan Weinberg. 2003. Metaskepticism: Meditations in ethno-epistemology. In The skeptics - Contemporary Essays, ed. Steven Luper, 227-247. Aldershot: Ashgate.

Nisbett, Richard E., Kaiping Peng, Incheol Choi, and Ara Norenzayan. 2001. Culture and systems of thought: Holistic versus analytic cognition. Psychological Review 108: 291-310. https://doi.org/10. 1037/0033-295X.108.2.291.

Open Science Collaboration. 2015. Estimating the reproducibility of psychological science. Science 349 (6251): aac4716. https://doi.org/10.1126/science.aac4716.

Pritchard, Duncan. 2004. Epistemic luck. Journal of Philosophical Research 29: 191-220. https://doi.org/ 10.5840/jpr_2004_18.

Putnam, Hilary. 1981. Reason, truth and history. Cambridge: Cambridge University Press.

Rose, David, et al. 2017. Behavioral circumscription and the folk psychology of belief: A study in ethnomentalizing. Thought: A Journal of Philosophy, 6(3): 193-203.

Seyedsayamdost, Hamid. 2015. On normativity and epistemic intuitions: failure of replication. Episteme 12 (1): 95-116. https://doi.org/10.1017/epi.2014.27.

van Dongen, Noah, Matteo Colombo, Felipe Romero, and Jan Sprenger. Intuitions about the reference of proper names: A meta-analysis. Review of Philosophy and Psychology (2020): 1-30.

Vogel, Jonathan. 1990. Are there counterexamples to the closure principle? In Doubting: Contemporary Perspectives on Scepticism, ed. Michael Roth and Glenn Ross, 13-27. Dordrecht: Springer.

Waterman, John, Chad Gonnerman, Karen Yan, and Joshua Alexander. 2018. Knowledge, certainty, and skepticism: A cross-cultural study. In Epistemology for the Rest of the World, ed. Stephen Stich, Masaharu Mizumoto, and Eric McCready, 188-214. Oxford: Oxford University Press.

Weinberg, Jonathan, Shaun Nichols, and Stephen Stich. 2001. Normativity and epistemic intuitions. Philosophical Topics 29 (1): 429-460. https://doi.org/10.5840/philtopics2001291/217. 
Williamson, Timothy. 2007. The philosophy of philosophy. New York: Routledge.

Wittgenstein, Ludwig. 1969. On certainty. Oxford: Blackwell.

Woolfolk, Robert L. 2013. Experimental philosophy: A methodological critique: Experimental philosophy. Metaphilosophy 44 (1-2): 79-87. https://doi.org/10.1111/meta.12016.

Ziółkowski, Adrian. 2021. The stability of philosophical intuitions: failed replications of Swain et al., Episteme, 18 (2), 328 - 346. https://doi.org/10.1017/epi.2019.20

Publisher's Note Springer Nature remains neutral with regard to jurisdictional claims in published maps and institutional affiliations. 